\title{
The Influence of Posture on Spirometric Values in Grade III Obese Patients
}

\author{
Ayrton Bentes Teixeira, TSA ${ }^{1}$, Ligia Andrade da S. Telles Mathias, TSA 2, Roberto Saad Junior ${ }^{3}$
}

\begin{abstract}
Summary: Teixeira AB, Mathias LAST, Saad Junior R - The Influence of Posture on Spirometric Values in Grade III Obese Patients.
Background and objectives: The change from the sitting position to supine position, general anesthesia, and surgical procedure reduce lung volumes and this effect can be greater in obese patients. The objective of the present study was to evaluate the influence of the sitting position, 30 dorsal inclination, and horizontal dorsal decubitus on spirometry of grade III obese patients.
\end{abstract}

Methods: Twenty-six adult patients in the preoperatory period were selected according to the following criteria: $\mathrm{BMI}>40 \mathrm{~kg} \cdot \mathrm{m}^{-2}$, age between 18 years and 60 years, and female gender. Variables analyzed included: age, weight, height, BMI, percentage of predictive values of FVC, FEV ${ }_{1}$, and $\mathrm{VEF}_{1} / \mathrm{FVC}$ in the sitting position $\left(90^{\circ}\right), 30^{\circ}$ dorsal elevation, and horizontal dorsal decubitus $\left(0^{\circ}\right)$. ANOVA, followed or not by Tukey test were used to compare mean predicted values on the different positions, considering significant a $p$ value lower than 0.05 .

Results: Percentage values of $\mathrm{FVC}, \mathrm{FEV}_{1}$, and $\mathrm{FEV}_{1} / \mathrm{FVC}$ ratio regarding predicted values in the sitting position $\left(90^{\circ}\right), 30^{\circ}$ dorsal elevation, and horizontal dorsal decubitus $\left(0^{\circ}\right)$, and $\mathrm{p}$ value of the corresponding statistical analysis were, respectively: $\mathrm{FVC}=92.8 \%, 88.2 \%$, and $86.5 \%$, $\mathrm{p}=0.301$ (ANOVA); FEV 1 : 93.1\%, 83.8\%, and 83.3\%, $\mathrm{p}=0.023$ (ANOVA), $\mathrm{p}=0.038$ (Tukey test $\left.-90^{\circ} \times 0{ }^{\circ}\right) ; \mathrm{FEV}_{1} / \mathrm{FVC}: 100,8 \%, 95.5 \%$, and $96.8 \%, p=0.035$ (ANOVA), $p=0.035$ (Tukey test $-90^{\circ} \times 30^{\circ}$ ).

Conclusions: Changes in position produced changes in spirometry results of patients with grade III obesity.

Keywords: Spirometry; Morbid Obesity; Preoperative Care.

๑2011 Elsevier Editora Ltda. All rights reserved.

\section{INTRODUCTION}

Obesity causes changes in the respiratory system; among them, changes in respiratory mechanics, muscular contraction and strength, pulmonary gas exchange, respiration control, lung function tests, and exercise capacity ${ }^{1}$. Total resistance of the respiratory system increases when obese patients change from the sitting position to the supine position ${ }^{2}$.

Spirometry is more commonly performed on the sitting position, although the supine position is also accepted. The most common abnormality in spirometry of obese patients is the reduction in expiratory reserve volume (ERV) and residual functional capacity (RFC). Vital capacity (VC) and total

Received from Faculdade de Ciências Médicas da Santa Casa de São Paulo (FCM-SCSP); Irmandade da Santa Casa de Misericórdia de São Paulo (ISCMSP), Brazil.

1. MSc in Medicine from Faculdade de Ciências Médicas da Santa Casa de São Paulo (FCM-SCSP); Assistant Physician of Irmandade da Santa Casa de Misericórdia de São Paulo (ISCMSP); Co-responsible for the CET-SCSP

2. Associate Professor of FCM-SCSP; Director of the Anesthesiology Department and Service of ISCMSP

3. Professor of FCM-SCSP; Chief of Thoracic Surgery Department of ISCMSP

Submitted on November 11, 2010.

Approved on April 4, 2011.

Correspondence to:

Dra. Ligia Andrade da S. Telles Mathias

Alameda Campinas 139/41

01404000 - São Paulo, SP, Brazil

E-mail: rtimao@uol.com.br lung capacity (TLC) show discrete variations, even in different obese populations and in grade III obesity ${ }^{3,4}$. Differences in position can significantly change the values of lung function tests. Gudmundsson et al. ${ }^{5}$ demonstrated that in obese individuals the forced vital capacity (FVC) is greater when it is measured with the patient in the supine compared to the sitting position. Forced expiratory volume in the first second $\left(\mathrm{FEV}_{1}\right)$ did not show differences between the sitting and supine positions.

General anesthesia and surgical procedures reduce lung volumes, and this effect can be greater in obese patients ${ }^{3,6-8}$. In normal individuals, the site of surgery affects the respiratory function, which is more frequently impaired after abdominal procedures in relation to non-abdominal procedures ${ }^{8}$.

The objective of this study was to determine whether the change from the sitting position $\left(90^{\circ}\right)$ to $30^{\circ}$ dorsal elevation and horizontal dorsal decubitus $\left(0^{\circ}\right)$ causes spirometric changes in grade III obese patients.

\section{METHODS}

After approval of the Ethics on Research Committee of the Irmandade da Santa Casa de Misericórdia de São Paulo (ISCMSP) and signing of the informed consent, adult patients from the Morbid Obesity outpatient clinic were selected for this transversal study. Inclusion criteria were: $\mathrm{BMl}>40 \mathrm{~kg} \cdot \mathrm{m}^{-2}$; age $>18$ years and $<60$ years; and female gender. The following were 
considered exclusion criteria: pregnancy; smokers; refusal to participate in the study; users of drugs that cause central nervous system depression; inability to perform the spirometry for lack of understanding; prior or current lung disease; and hearing disease that prevented verbal communication.

The size of the study population was calculated to identify a $30 \%$ difference among variables according to the analysis power based on the following parameters: type I error $(\alpha=0.05)$ and type II error $(\beta=0.8)$. For this, 24 patients would be necessary and, assuming the possibility of losses, we decided to include 26 patients.

In the Morbid Obesity Outpatient Clinic, the spirometry was explained to the patient, the spirometer was shown to the patient, and the position of the mouth piece was demonstrated. Then, the test was performed, according to the criteria of the American Thoracic Society (ATS) ${ }^{9}$. Measurements were performed, first, in the sitting position $\left(90^{\circ}\right)$, followed by the $30^{\circ}$ dorsal inclination, with at least three, but no more than eight, measurements. After these two steps, patients were transferred to another room where they underwent pre-anesthetic evaluation performed by another physician who was not linked to the investigation. After the pre-anesthetic evaluation, the patient returned to the exam room and the horizontal dorsal decubitus $\left(0^{\circ}\right)$ spirometry was performed.

A portable spirometer with a SpiroCard ${ }^{\circledR}$ flow sensor was used for analysis and plotting the volume-time and flow-volume charts, according to the ATS spirometric criteria.
Variables investigated included: age, weight, height, $\mathrm{BMI}, \mathrm{FVC}, \mathrm{FEV}_{1}, \mathrm{FEV}_{1} / \mathrm{FVC}$ ratio in the sitting position $\left(90^{\circ}\right), 30^{\circ}$ dorsal elevation, and horizontal dorsal decubitus $\left(0^{\circ}\right)$ as percentage of predicted values according to Pereira et al. 10

The Kolmogorov-Smirnov test evaluated all variables in this study regarding the normalcy of distribution. Comparison of predicted values was done by analysis of variance (ANOVA), and the Tukey test was used to compare the different positions, considering significant whenever $p<0.05$.

\section{RESULTS}

Twenty-six female patients participated in this study. Mean values and standard deviation of anthropometric data were: age (years), $42.07 \pm 10.79$; weight $(\mathrm{kg}), 123.51 \pm 17.43$; height (m), $1.59 \pm 0.05$; and BMl $\left(\mathrm{kg} \cdot \mathrm{m}^{-2}\right), 48.51 \pm 6.19$.

All variable were within normal distribution according to the Kolmogorov-Smirnov test $(p>0.05)$.

Table I shows the results of mean percentage of predicted values for $\mathrm{FVC}, \mathrm{FEV}_{1}$, and $\mathrm{FEV}_{1} / \mathrm{FVC}$, and the value of $\mathrm{p}$ on analysis of variance on all three positions.

Tables II and III show the results of the Tukey test for FEV and the $\mathrm{FEV}_{1} / \mathrm{FVC}$ ratio, respectively, among the different positions.

Table I - Mean Percentages of the Predicted Values of FVC, $\mathrm{FEV}_{1}$, and $\mathrm{FEV}_{1} / \mathrm{FVC}$ in the Sitting Position $\left(90^{\circ}\right)$, $30^{\circ}$ Dorsal Elevation, and Horizontal Dorsal Decubitus $\left(0^{\circ}\right)$, and Analysis of Variance (ANOVA)

\begin{tabular}{|c|c|c|c|c|}
\hline & Sitting Position & 30 Dorsal Elevation & HDD & $\mathrm{p}(\mathrm{ANOVA})$ \\
\hline $\mathrm{FEV}_{1}$ & 93.08 & 83.78 & 83.29 & $0.023^{*}$ \\
\hline $\mathrm{FEV}_{1} / \mathrm{FVC}$ & 100.76 & 95.50 & 96.81 & $0.035^{\star}$ \\
\hline
\end{tabular}

FVC: forced vital capacity; $\mathrm{FEV}_{1}$ : forced expiratory volume in the first second; $\mathrm{FEV}_{1} / \mathrm{FVC}$ ratio: forced expiratory volume in the first second/forced vital capacity ratio; HDD: horizontal dorsal decubitus; ANOVA: analysis of variance; ${ }^{*}=p<0.05$.

Table II - Comparison of the FEV 1 in the Different Positions by the Tukey Test

\begin{tabular}{llll}
\hline & Sitting Position & $30^{\circ}$ Dorsal Elevation & HDD \\
\hline Sitting Position & - & $\mathbf{0 . 0 5 1}$ & $\mathbf{0 . 0 3 8 ^ { * }}$ \\
$30^{\circ}$ Dorsal Elevation & - & - & 0.992 \\
\hline
\end{tabular}

$\mathrm{FEV}_{1}$ : forced expiratory volume in the first second; HDD: horizontal dorsal decubitus; ${ }^{*}=p<0.05$.

Table III - Comparison of the FEV 1 /FVC in the Different Positions by the Tukey Test

\begin{tabular}{llll} 
& Sitting Position & 30 Dorsal Elevation & HDD \\
\hline Sitting Position & - & $\mathbf{0 . 0 3 5 ^ { \star }}$ & 0.142 \\
$30^{\circ}$ Dorsal Elevation & - & - & 0.805 \\
\hline
\end{tabular}

$\mathrm{FEV}_{1} / \mathrm{FVC}$ ratio: forced expiratory volume in the first second; HDD: horizontal dorsal decubitus; ${ }^{*}=\mathrm{p}<0.05$. 


\section{DISCUSSION}

The prevalence of grade III obesity among women is greater than in men and, in our service, it is not different. Due to difficulties of having homogenous groups of obese patients of both genders and the fact that lung volumes and the $\mathrm{FEV}_{1} / \mathrm{FVC}$ ratio are different in both genders, we decided to include only females. Elderly patients and/or smokers were also excluded, since both conditions change the results of spirometry.

The correlation of varying the decubitus and lung function in patients with grade III obesity in the preoperative period was evaluated by different authors using other variables not used in the present study 8,11,12. We did not find in the literature studies comparing predicted FVC, $\mathrm{FEV}_{1}$, and $\mathrm{FEV}_{1} / \mathrm{FVC}$ ratio on all three positions in the preoperative period of patients with grade III obesity.

Several studies have included preoperative FVC of obese patients only in the sitting position ${ }^{7,10-14}$. Some of them presented absolute values of spirometric variables ${ }^{8,11-14}$. Comparison of those results with the present study was not possible, since the normalcy pattern of spirometric values varies according to the anthropometric characteristics of weight, height, gender, and race, and has specific formulas determined by different authors. We used the reference values defined by Pereira et al. 10 in our study.

The values observed in the present study on the sitting position $\left(90^{\circ}\right)$ were similar to those observed by Rasslam ${ }^{15}$ in a study that evaluated, in patients of both genders, the effects of grades I and II obesity on spirometry. Mean FVC of $101.0 \%$ was observed in female patients with mean BMl of $34.2 \mathrm{~kg} \cdot \mathrm{m}^{-2}$.

On the study of Sarikaya et al. ${ }^{14}$, comparing spirometries of non-obese patients and grades I, II, and III obese patients in the sitting position, higher values in the group of grade III obesity (BMl $>40 \mathrm{~kg} \cdot \mathrm{m}^{-2} ; 86 \%$ females) were observed, with mean FVC of $108.26 \%$. Domingos-Benício et al. ${ }^{16}$ compared the spirometry of eutrophic and obese (grades I, II, and III) non-smoker volunteers of both genders on orthostatic, sitting, and supine positions. The numeric values were not included in the publication, only histograms, showing that the mean FVC value of grade III obese patients in the sitting position is between $90 \%$ and $95 \%$. In their results, as well as in ours, there is a reduction of spirometry results in the supine position.
The mean $\mathrm{FEV}_{1}$ value in the sitting position observed in the present study, $93.1 \%$, was similar to that observed by other authors in studies with comparable methods: between $90.0 \%$ and $96.0 \%{ }^{14,16-18}$.

Razi and Moosavi ${ }^{17}$, in a study with patients of both genders, observed that, in a group of non-asthmatic patients in the sitting position, their $\mathrm{FEV}_{1}=101.0 \%{ }^{17}$. However, the mean BMl of $36.69 \mathrm{~kg} \cdot \mathrm{m}^{-2}$ of that study was smaller than that of our study, justifying higher $\mathrm{FEV}_{1}$ values.

The mean value of the $\mathrm{FEV}_{1} / \mathrm{FVC}$ ratio in the sitting position observed in the present study was $100.76 \%$, higher than the values observed in some studies with comparable methods $(76.5 \% \text { and } 86.0 \%)^{14}$, but similar to that observed by Rasslam (100.0\%) ${ }^{15}$.

Studies with male patients, smokers and non-smokers, showed lower $F E V_{1} / F V C$ ratio: $81.6 \%$ and $82.5 \%$, as well as in studies with patients of both genders: between $80 \%$ and $86.4 \%^{9,19,20 \text {. }}$

The results regarding the horizontal position confirm the results of Domingos-Benício et al. ${ }^{16}$, the only one found in the literature that used a similar method and evaluated patients in horizontal dorsal decubitus. They reported a statistically significant reduction in $\mathrm{FVC}, \mathrm{FEV}_{1}$, and $\mathrm{FEV}_{1} / \mathrm{FVC}$ ratio in dorsal decubitus in relation to the sitting position, which was not observed in the present study.

The present study demonstrated that, in adult female patients with grade III obesity, non-smokers, without lung disease, $30^{\circ}$ dorsal inclination and horizontal dorsal decubitus $\left(0^{\circ}\right)$ cause changes in spirometry. This has practical implications, since the beds in the recovery unit at ISCMSP reach, the most, an inclination of $30^{\circ}$. Note that patients with grade III obesity have difficulties in maintaining the semi-sitting position in the postoperative period. Even at $30^{\circ}$ inclination, very often they slide in the bed, resulting in a lower inclination, which potentially hinders their respiratory pattern.

One can infer that male and elderly patients also suffer influence of the decubitus; however, similar studies with those groups should be performed.

Thus, despite the limitations of the present study, it is important to evaluate patients with grade III obesity in the immediate postoperative period, trying to maintain them more elevated than $30^{\circ}$. 